\title{
Effect of Cracking on Corrosion of Steel in Concrete
}

\author{
Faiz Uddin Ahmed Shaikh*
}

(Received August 25, 2016, Accepted January 7, 2018)

\begin{abstract}
It is generally recognized that cracks provide easy access to ingress of chlorides in concrete and hence, the initiation of corrosion of steel in cracked concrete occurs at early stage. However, wide variety of results on the effect of crack widths on corrosion of steel in concrete are reported in many studies. Apart from crack width, the crack depths, cracking frequency and healing of cracks also influence the corrosion of steel in concrete. This paper presents a comprehensive review and summarised the results on the effect of cracking on corrosion of steel in concrete. The effect of crack widths on the diffusion of chlorides ions and carbon-dioxide is also discussed in this paper. Among all available results, a correlation between the corrosion current and the crack widths up to $0.3 \mathrm{~mm}$ can be established, however, no distinct trends are observed beyond that crack width. Conflicting results on the effect of crack widths on chloride ion diffusion are also reported. The longitudinal crack causes more severe corrosion of steel in concrete than transverse cracks of same width. Cracked concrete containing supplementary cementitious materials exhibited superior corrosion resistance than cracked ordinary Portland cement concrete of same width of transverse as well as longitudinal cracks. The same is also true in the case of lower water-binder ratios of cracked concrete. The increase in crack depth increased the chloride diffusion; however, the corrosion test shows an opposite trend. Conflicting results on the effect of crack frequency on corrosion of steel are also reported.
\end{abstract}

Keywords: corrosion, crack width, crack depth, crack frequency, chlorides, carbonation.

\section{Introduction}

Concrete is the most widely used construction materials in the world due to its low cost and easy availability of its ingredients. It also exhibits excellent strength properties in compression. However, it easily cracks in tension, flexure and shear as well as due to various environmental factors such as thermal cracking, shrinkage cracking, freeze-thaw, etc., during its service life. The formation of cracks adversely affect its durability properties with most significant effect on the de-passivation of reinforcing steel in reinforced concrete (RC), resulting in corrosion of steel. The presence of cracks shorten the corrosion initiation time of steel and also accelerates the propagation of corrosion during service life resulting in significant corrosion induced damage and loss of sectional and load carrying capacity of RC structures. The formation of cracks in $\mathrm{RC}$ is unavoidable due to its low tensile strength. The cracks thus form in concrete varies in widths, numbers, geometry, depths, etc. (Mehta and Gerwick 1982). These factors affect the initiation and propagation of corrosion of steel in RC. Considerable number of publications reported the research results on the corrosion of steel in cracked concrete. Most of them studied

Department of Civil Engineering, Curtin University, Perth, WA 6102, Australia.

*Corresponding Author; E-mail: s.ahmed@curtin.edu.au Copyright (c) The Author(s) 2018. This article is an open access publication the corrosion of steel in concrete with different crack widths, while others, in few numbers, studied the effects of number of cracks and their depths on the corrosion of steel in concrete. Conflicting results on the relationship between the crack widths and corrosion of steel in concrete are also reported. In most of the above studies, the corrosion of steel was considered due to penetration of chloride ions. However, carbonation also induces corrosion of steel in concrete and especially in cracked concrete. Very few studies, so far, are reported on this aspect. While many results on the effect of cracks on corrosion of steel in concrete are reported, hardly any paper exists that provides a comprehensive summary and review of existing available results on steel corrosion in cracked concrete, the relationship between crack widths and corrosion, effects of other parameters of crack on corrosion of steel in concrete in a single report. Therefore, this paper is prepared to fill this gap in the state of knowledge on the effects of cracks on corrosion of steel in concrete.

\section{Effect of Crack Widths}

Surface crack width is considered to be the most important parameter that affects the corrosion of steel in concrete. Cracks on concrete surface which are perpendicular to the reinforcing steel known as "transverse cracks" and those parallel to longitudinal reinforcing bars as known as "longitudinal cracks”. Generally, the transverse cracks are most 
common in RC. Longitudinal cracks generally form after the corrosion of steel and are considered more dangerous than transverse cracks for corrosion as more area of steel is exposed to the aggressive environment. Another reason is that longitudinal cracks are the evidence of the critical development of corrosion on the reinforcing steel. Most of the published results studied the effects of transverse cracks of different widths on the corrosion of steel. While it is generally accepted that appropriate crack width might accelerate the corrosion initiation, however, there are conflicting results and debate about the effect of cracks on corrosion initiation (Darwin et al. 1985). Table 1 shows the summary of available results on the corrosion of steel in cracked concrete with different transverse crack widths. It can be seen that different researchers used different widths of cracks, water-cement ratios, concrete types, corrosion periods as well as different methods of corrosion evaluation. Therefore, a direct relationship on the effect of widths of transverse cracks on the corrosion of steel in cracked concrete based on available data is difficult to establish. Even with the same researcher no trend on the widths of cracks with corrosion of steel can also be seen. For example, Mohammed et al. (2001a), Sistonen et al. (2007), Quero et al. (2010), Schiebl and Raupach (1997), etc., did not noticed any increasing trend of corrosion of steel in concrete with increase in transverse crack widths. While, others results, e.g., Otieno et al. (2010), Sahmaran and Yaman (2008), Montes et al. (2004), Scott and Alexander (2007), etc., show such increasing trend. Figures 1 and 2 show the rate of corrosion of steel in concrete having different widths of cracks and the mass loss compiled from different studies. It can also be seen that in a broader scale no relationships between the crack widths and the corrosion can be established. However, at smaller crack widths up to $0.3 \mathrm{~mm}$ an increasing trend of corrosion of steel with increase in crack width can be seen. It can also be seen that the scatter of results in the range of bigger crack widths, e.g., at 0.5 and $0.7 \mathrm{~mm}$ are more pronounced than that in the range of the smaller crack widths.

\section{Effect of Longitudinal Cracks}

While transverse cracks are common in RC structures, longitudinal cracks are also formed due to shrinkage cracking, plastic settlement of concrete, etc. In terms of a critical development of corrosion of steel in concrete, the longitudinal cracks parallel to steel bars are more dangerous than transverse cracks perpendicular to steel bars because they provide easy access of chlorides, moisture and oxygen to a wide area of steel reinforcement and it accelerates the further development of corrosion. In case of transverse cracks, however, the cathode area is situated between the cracks, where moisture and oxygen have to reach the embedded steel through sound concrete in order to enable the corrosion process. Therefore, longitudinal cracks can significantly shorten the service life of concrete structures. The only reported study on the effect of longitudinal crack on corrosion of steel in concrete is by Poursaee and Hansson (2008) where the effect of $0.1 \mathrm{~mm}$ wide longitudinal crack on corrosion of steel bar is evaluated after 128 weeks of corrosion test. In their study they also evaluated the effects of supplementary cementitious materials (SCMs) by which concrete was modified by containing slag and fly ash. Their results are compiled and are shown in Fig. 3. It can be seen that the corrosion current density of reinforcing steel in transversely cracked concrete is lower than those in longitudinally cracked concretes of same width. However, it should be noted that the clear cover in the case of transverse crack is three to four times more than the case of longitudinal crack and this could be the reason for significantly lower current density in transversely cracked concrete. The positive influence of thicker concrete cover of same crack width in reducing the corrosion current density in ordinary concrete as well as in SCMs modified concretes is also reported by Scott and Alexander (2007) and Raupach (1996) as can be seen in Table 1. On the other hand, no significant improvements due to the effect of SCMs can be observed on corrosion of steel in longitudinally cracked concrete.

\section{Effect of Crack Frequency}

Crack frequency is defined as the number of cracks per specific length. The crack frequency of transverse cracks also effects the corrosion of steel in concrete. In a study, Arya and Darko (1996) evaluated the effect of crack frequency on the corrosion of steel in concrete containing transverse cracks of same depths and total crack width of $2.4 \mathrm{~mm}$. Their results (see Fig. 4) show that the corrosion of steel increases with increase in crack frequency, except the crack frequency of 20 where self-healing of cracks was observed in that beam reported by the authors. In a subsequent study, however, Schiebl and Raupach (1997) reported a completely different observation where the increase in crack frequency decreased the corrosion rate (see Fig. 5). They also observed that by doubling the crack spacing or in other words by decreasing the number of cracks into half the corrosion rate is doubled. They argued that by reducing the crack spacing through increasing the number of cracks, the size of the cathode areas between the cracks are decreased, which reduced the corrosion rate. This hypothesis also found to explain the low corrosion current of steel embedded in strain hardening cementitious composites (SHCCs) containing closely spaced multiple cracks (e.g., in Ahmed and Mihashi 2010).

\section{Effect of Crack Depth}

In addition to crack width, crack depth is also a key parameter; especially, under loading the crack depth increases during all stages in the life of a concrete structure which strongly affects the chloride ions penetration depth. However, studies about crack depth affecting the chloride penetration and subsequent steel corrosion are rarely available. Moreover, shape of crack depth might also influence 


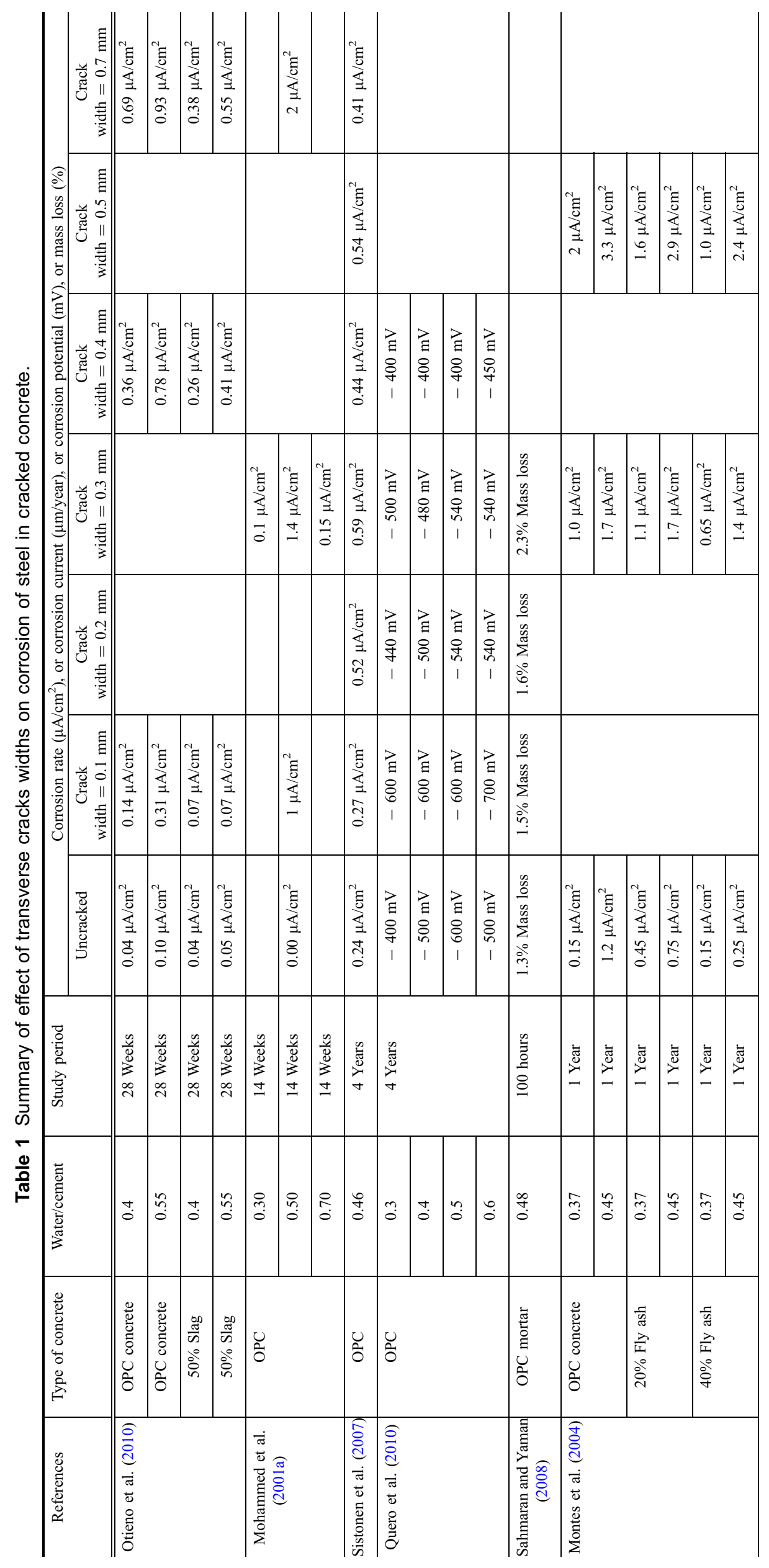




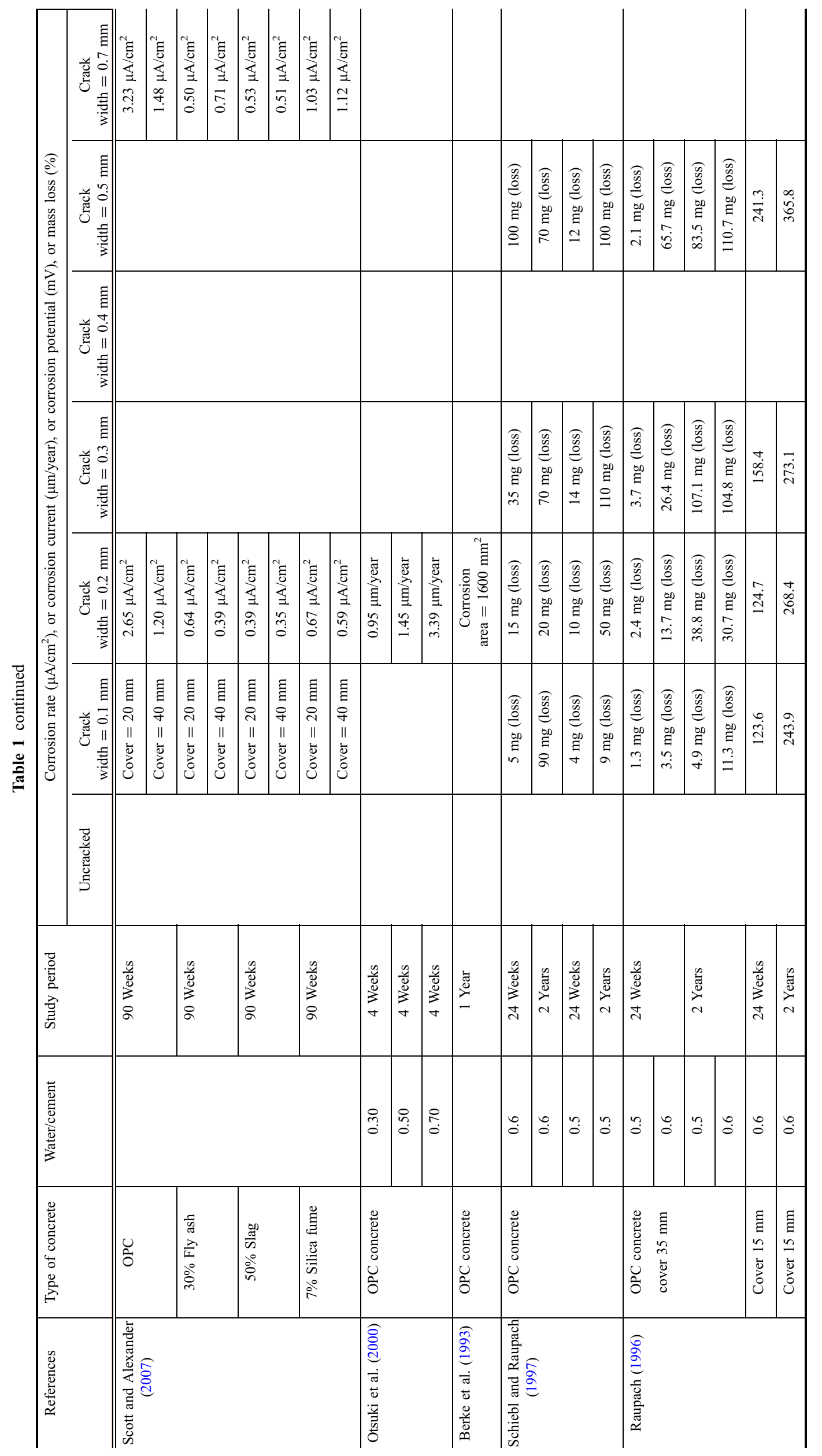




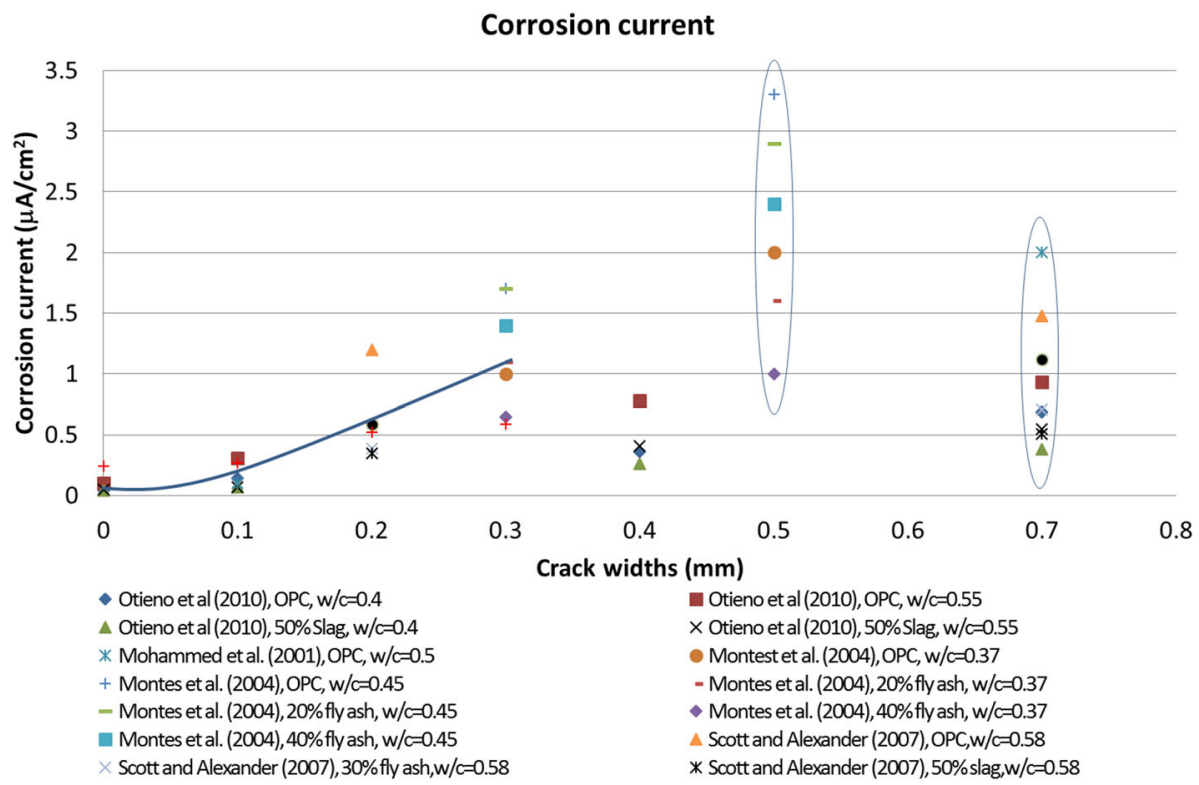

Fig. 1 Effect of transverse crack widths on corrosion of steel in different concretes.

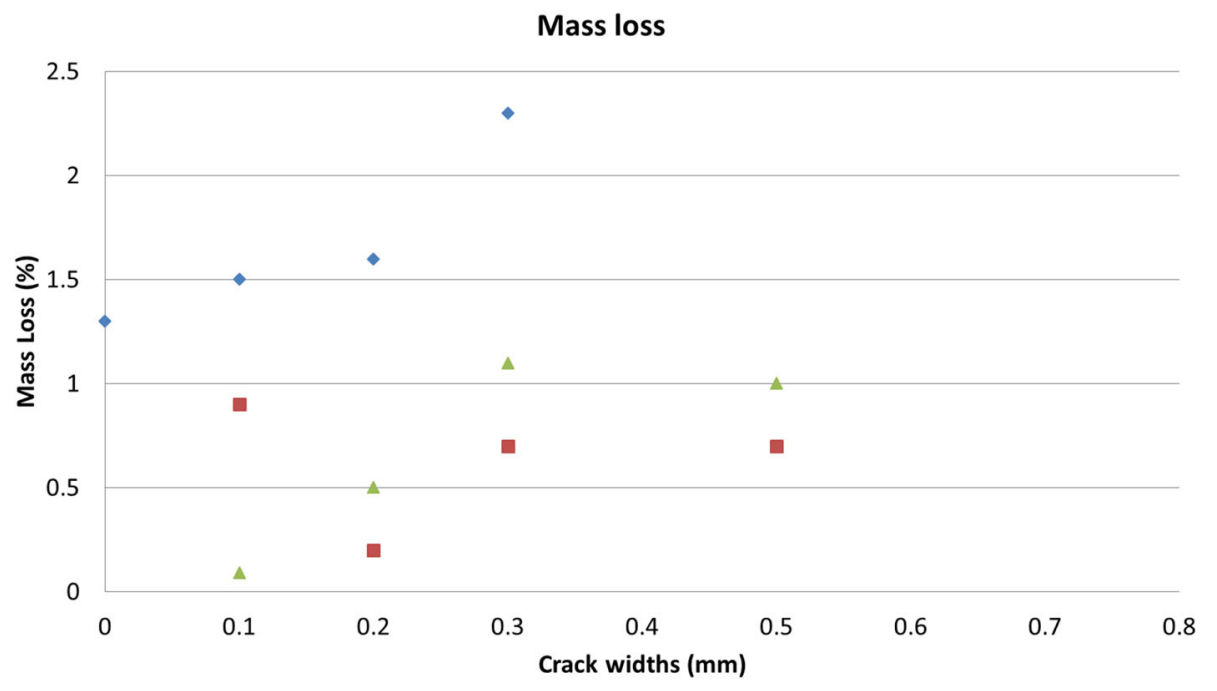

- Sahmaran and Yaman (2008), w/c=0.48 a Schiebl and Raupach (1997), w/c=0.6

$\triangle$ Schiebl and Raupach (1997), w/c=0.5

Fig. 2 Effect of crack widths on steel loss due to corrosion of steel in different concretes.

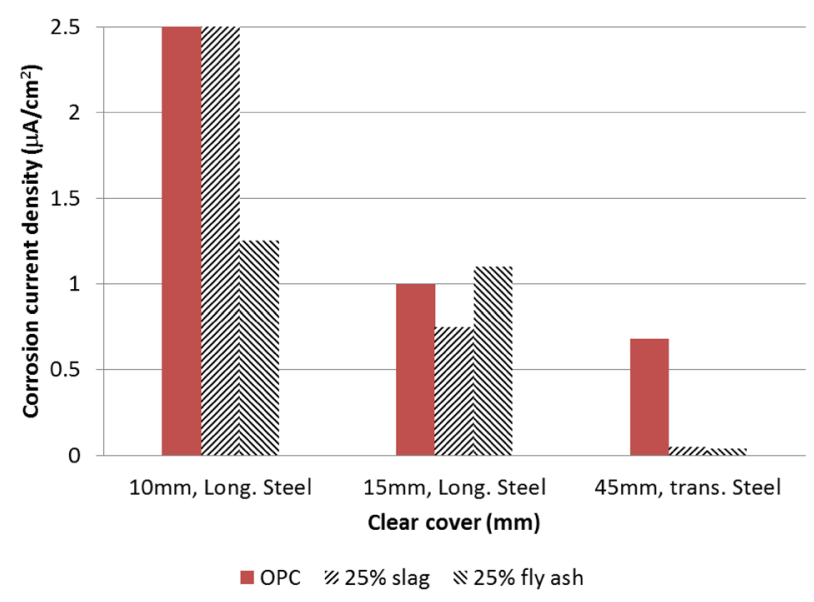

Fig. 3 Effect of longitudinal cracks on corrosion of steel in concretes. Data from Poursaee and Hansson (2008) the chloride penetration and corrosion of steel as it depends on the concrete cover. The thicker the concrete cover the higher the possibility of forming "V-shape" cracks than "parallel-wall" cracks in the case of thin concrete cover under bending loads. In V-shape cracks the width of crack towards the reinforcing steel is smaller than at the concrete surface. In a study, Audenaert et al. (2009) evaluated the effect of different crack depths of 5, 10, 15 and $20 \mathrm{~mm}$ on the penetration of chlorides in concrete with parallel-wall crack width of $0.2 \mathrm{~mm}$. It was observed that the chloride penetration depth increased with increase in crack depths irrespective of immersion periods of cracked specimens in salt solution. The effect of depths of parallel-wall cracks on chloride diffusion of concretes with different $\mathrm{w} / \mathrm{c}$ ratios is also studied by Stitmannaithum et al. (2013), where increase in chloride diffusion with increase in crack depth and w/c 


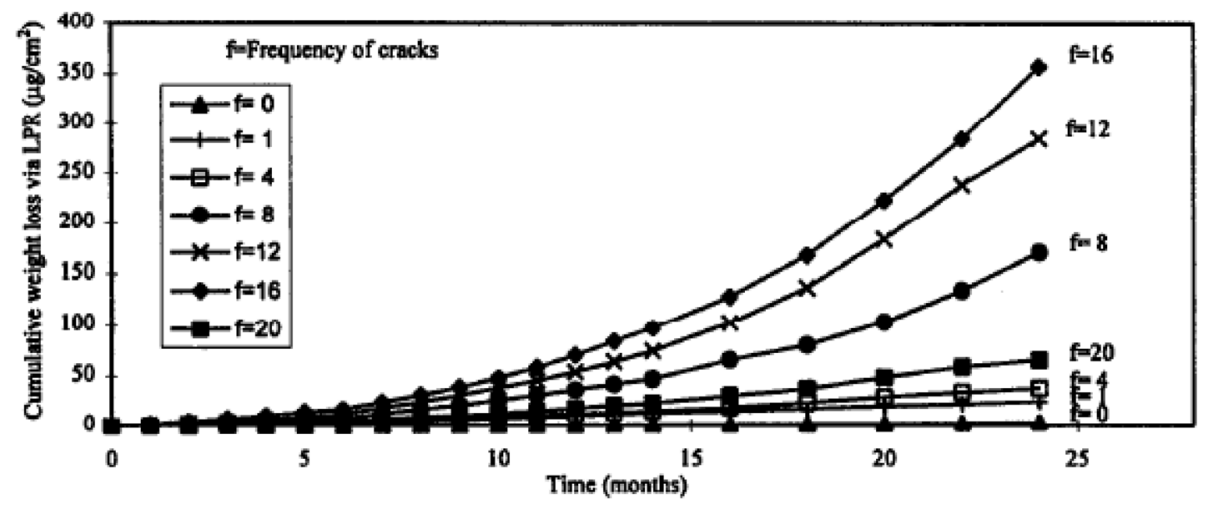

Fig. 4 Effect of crack frequency on cumulative weight loss due to corrosion (Arya and Darko 1996).

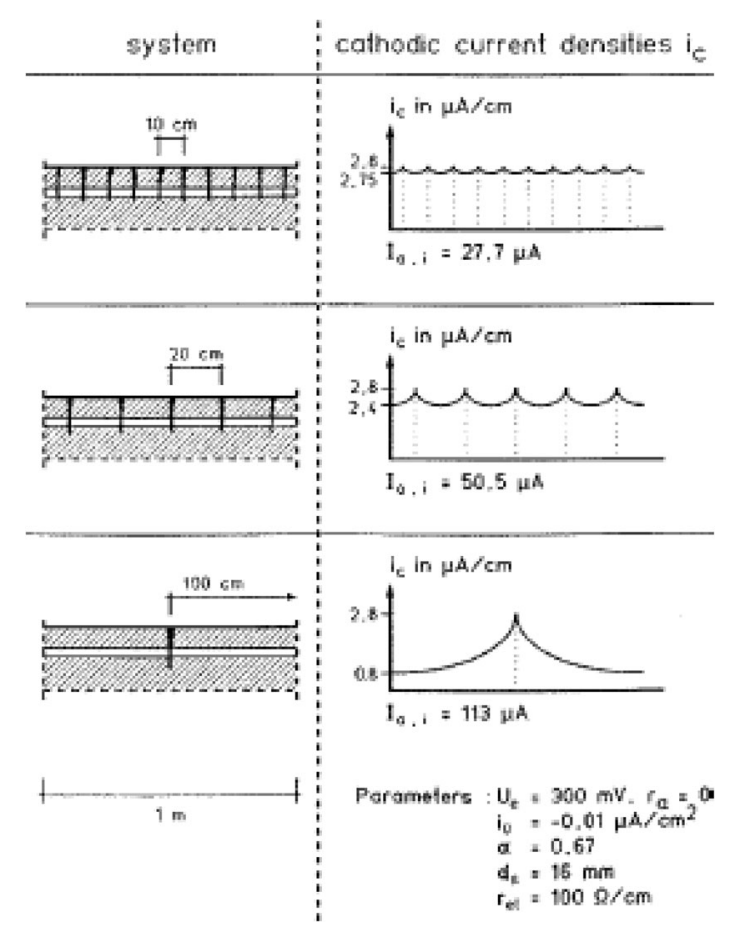

Fig. 5 Effect of number of cracks on corrosion current of steel in concrete (Schiebl and Raupach 1997).

ratios is also reported (see Fig. 6). While no corrosion test results on the effect of widths of parallel-face cracks are available, it can be argued that in real situation the corrosion of steel will be less in V-shape cracks. This has been reflected in Scott and Alexander's (2007) study, where corrosion current decreased with increase in concrete cover depth or in other words cracks depth. It should be noted that in their study cracks in the concrete cover were formed through three points bending of $\mathrm{RC}$ beam specimens, which supposed to form V-shaped cracks. Therefore, appropriate experimental set-up is required to interconnect the impact of crack width, crack frequency and crack depth on chloride induced corrosion in a simulated marine environment in

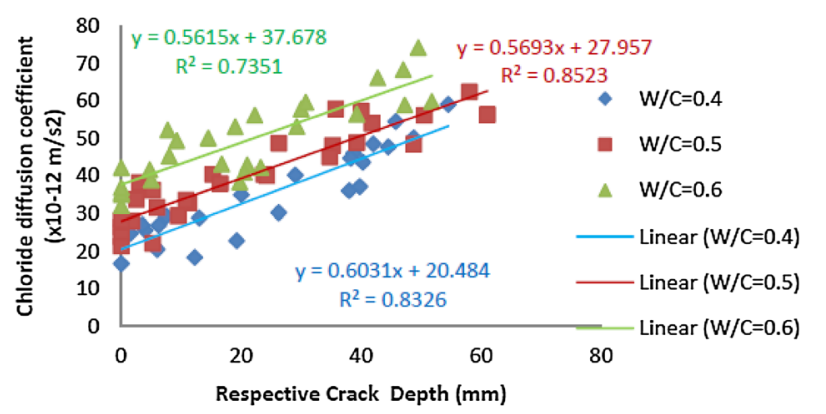

Fig. 6 Effect of crack depths and water-cement ratio on chloride diffusion of cracked concretes (Stitmannaithum et al. 2013)

future for better understanding of their influence on service life of RC structures (Blagojevic et al. 2012).

\section{Effects of SCMs}

The effects of crack widths on corrosion of steel in SCMs modified cracked concretes are also evaluated by a number of researchers and their summarised results are presented in Fig. 7. It can be seen that the corrosion currents of cracked SCMs modified concretes are lower than its counterpart ordinary Portland cement (OPC) concrete for all crack widths. The better corrosion resistance of cracked SCMs modified concretes can be attributed to their denser microstructure and lower porosity than OPC concrete. Although in the crack area (anode zone) the access of aggressive substances in both OPC and SCMs modified concretes is same, the availability of oxygen and moisture in the cathode region next to the anode region (crack area) (see Fig. 8) should be much lower in SCMs modified concretes due to its dense microstructure than in OPC concrete and by controlling the availability of oxygen and moisture in the cathode region the corrosion of steel in concrete can be significantly reduced. 
Corrosion current

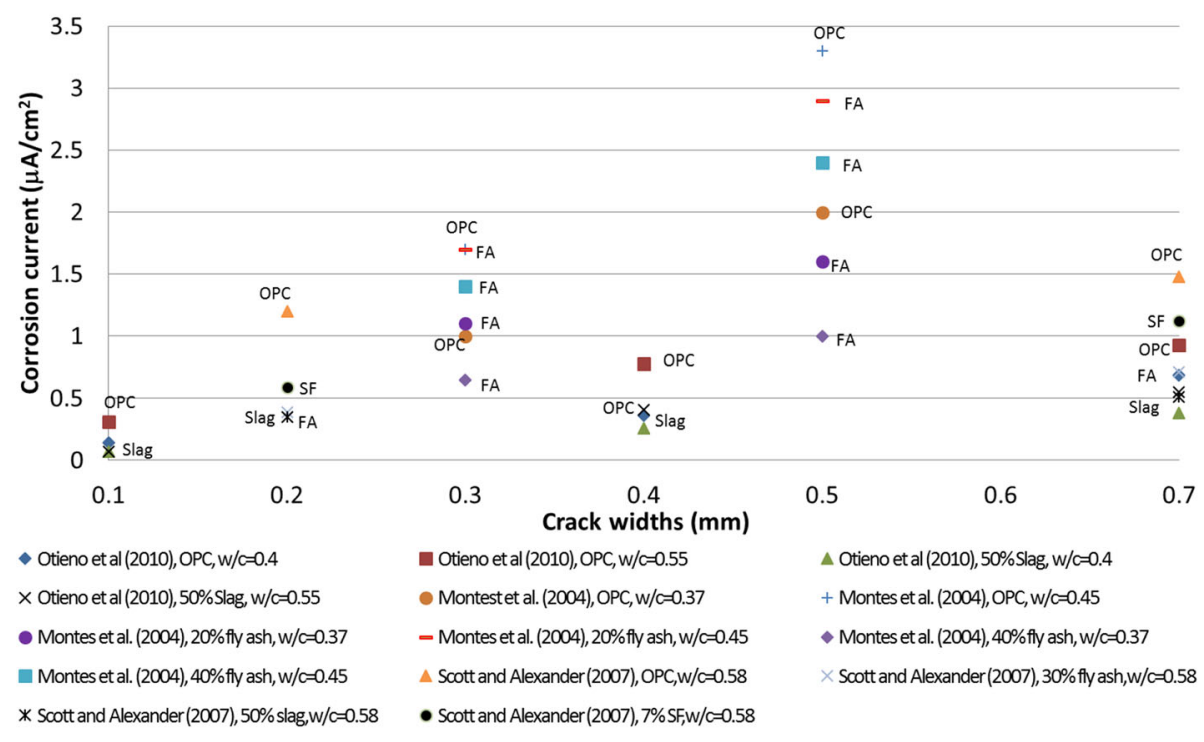

Fig. 7 Effect of SCMs on corrosion of steel in concrete having different crack widths.

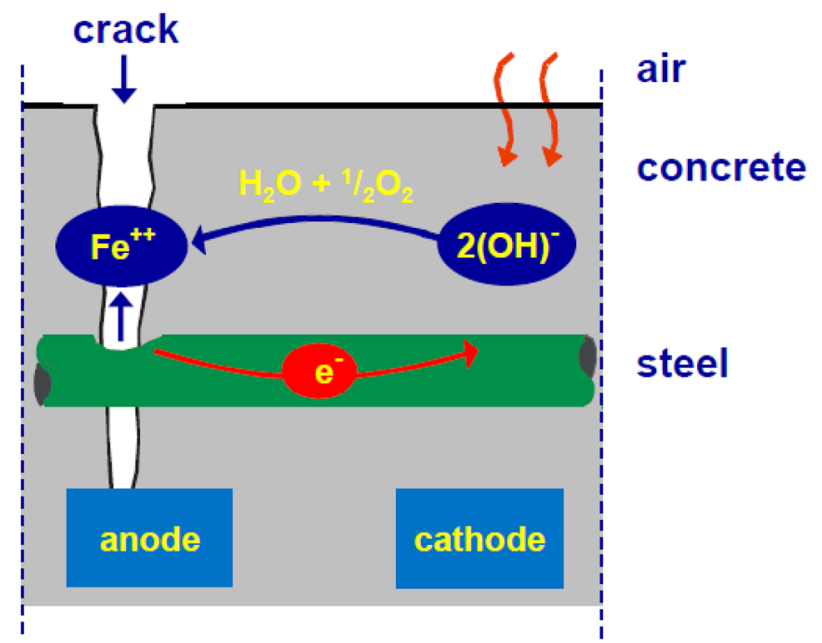

Fig. 8 Schematic of corrosion cells formed in cracked concrete.

\section{Effect of Crack Width on Carbonation Induced Corrosion of Steel}

While extensive studies on the effect of cracking on chloride penetration and chloride induced corrosion of steel in cracked concrete are conducted, relatively very few are reported on carbonation induced corrosion of steel in cracked concrete. Carbon-dioxide reduces the $\mathrm{pH}$ of the pore solution in the concrete which destroys passive film on steel bars and initiate corrosion. Generally, uniform corrosion of steel bars happens due to carbonation and this type of corrosion occurs in dry concrete as $\mathrm{CO}_{2}$ can't diffuse through the saturated cracks or pores. Contrary to chloride environment, the effect of crack openings on the diffusion of carbon dioxide to the steel-concrete interface and subsequent corrosion of steel in concrete has not been widely studied. AlAhmad et al. (2009) reported an investigation on the influence of crack opening on carbon dioxide penetration in cracked ring-shaped mortar specimens. They found that the crack opening significantly affects the ability of carbon dioxide to diffuse along the crack walls. On the other hand, Dang et al. (2013) reported a study on the effects of cracks on both initiation and propagation of corrosion of re-bar due to carbonation. Ring shaped mortar specimens reinforced with $8 \mathrm{~mm}$ diameter steel bar were cracked with different crack widths ranging from 0.12 to $0.6 \mathrm{~mm}$. Then the specimens were subjected to carbon dioxide environment for different durations to assess the carbonation profile in cracks and along the interface between steel and concrete and corrosion of steel. The authors reported that irrespective of width of cracks, the carbon dioxide reached the interface between the steel and the mortar and caused corrosion of steel in the mortar specimen. Miyazato and Otsuki (2010) also studied the effect of crack width of $0.5 \mathrm{~mm}$ on carbonation induced corrosion of steel in concrete with various $\mathrm{w} / \mathrm{c}$ ratios of $0.3,0.5$ and 0.7 and reported that the corrosion of steel increased with increase in $\mathrm{w} / \mathrm{c}$ ratios.

\section{Effect of Crack Widths on Chloride Permeability}

Availability of chloride ions is one of the important factors for initiation of corrosion of steel in concrete, because the availability of certain amount of chlorides above the threshold content de-passivates the steel in the concrete. Therefore, the availability of chloride ions above the threshold limit has a direct relationship with corrosion of steel in concrete and the presence of cracks thus has obvious influence on the penetration of chlorides into concrete. Several researchers studied the permeability of chlorides through cracked concretes. Like the corrosion, conflicting results on the effect of crack widths on chloride penetration are also available. For example, Aldea et al. (1999) evaluated the effects of various crack widths ranging from 0.05 to 


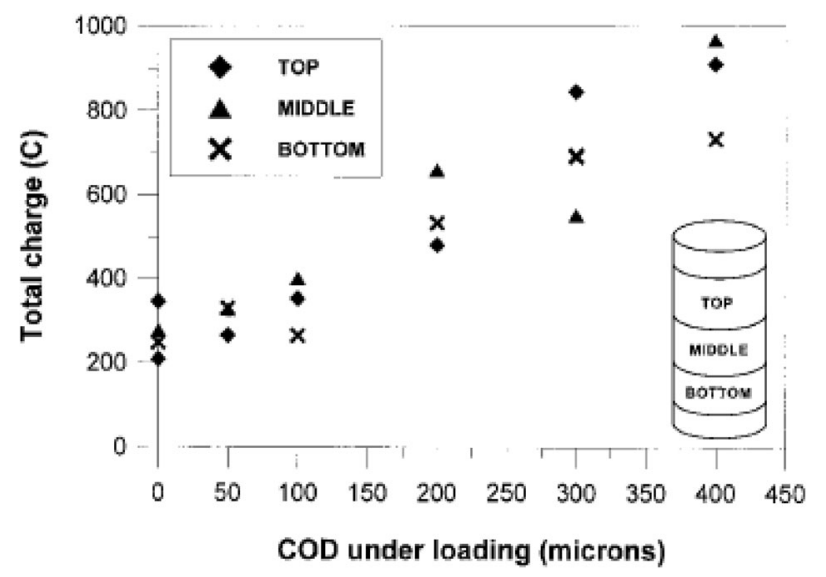

Fig. 9 Effect of crack widths on chloride ion penetration (Aldea et al. 1999) (COD crack widths on the concrete surface).

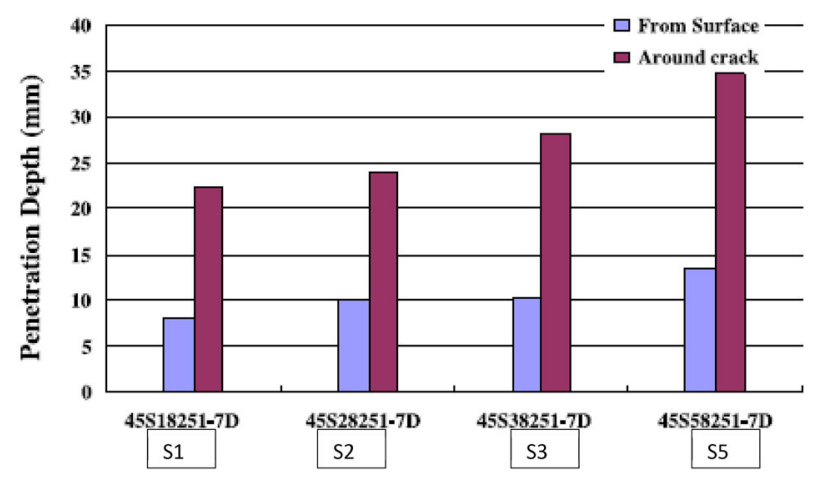

Fig. 10 Effect of crack widths on chloride penetration depth (Win et al. 2004) (note S1, S2, S3 and S5 indicates the crack widths of $0.1,0.2,0.3$ and $0.5 \mathrm{~mm}$, respectively).

$0.4 \mathrm{~mm}$ on the chloride penetration in concrete and reported an increasing trend of chloride penetration in terms of total charge passed with increase in crack widths (see Fig. 9). In another study, Win et al. (2004) and Ismail et al. (2008) also reported increasing trend of chloride ion penetration and chloride ion diffusion with increase in crack widths as can be seen in Figs. 10 and 11, respectively. Ismail et al. (2008) also reported no chloride ion diffusion below the crack widths of $0.03 \mathrm{~mm}$ with the ability of self-healing to impede chloride diffusion at crack width below $0.06 \mathrm{~mm}$. Djerbi et al. (2008) also reported increase in chloride diffusion coefficient with increase in crack widths up to about $0.25 \mathrm{~mm}$ (see Fig. 12). They also observed that chloride ion diffusion is higher in cracked OPC concrete than that containing silica fume for each crack width. However, Rodriguez and Hooton (2003) and Jang et al. (2011) did not observed any trends of chloride ion diffusion with different crack widths (see Figs. 13, 14). The chloride ion diffusion was found to be much lower in the case of cracked concrete containing slag for all measured crack widths in Rodriguez and Hooton's study with almost same chloride diffusion for all crack widths up to $0.6 \mathrm{~mm}$ (see Fig. 13b).

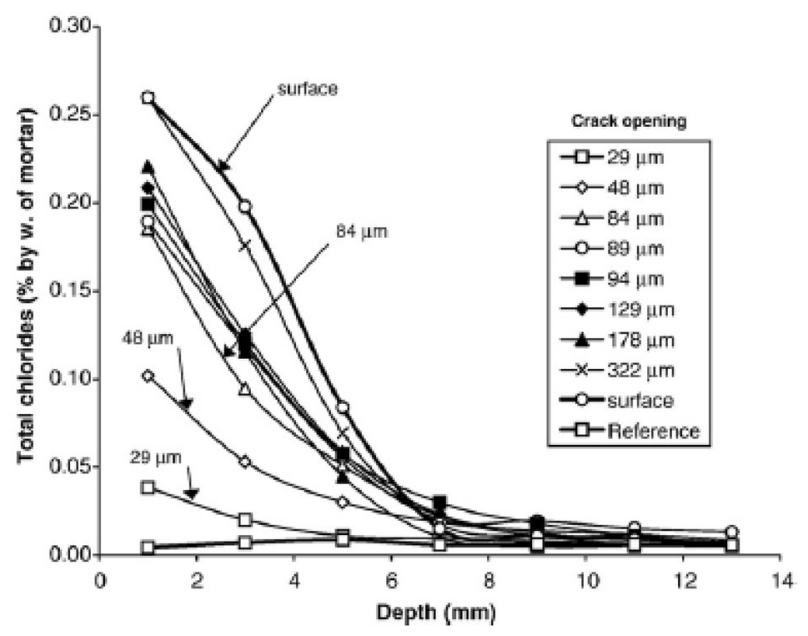

Fig. 11 Effect of crack widths on total chloride penetration (Ismail et al. 2008).

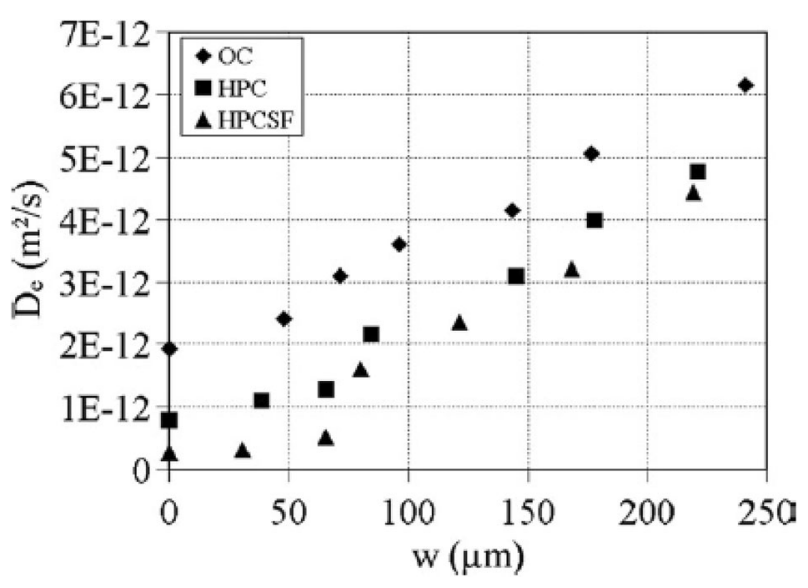

Fig. 12 Chloride ion diffusion in cracked OPC concrete, HPC concrete and that containing silica fume (Djerbi et al. 2008).

\section{Effect of Cracking on Oxygen Permeability of Concrete}

In addition to the presence of chlorides, $\mathrm{CO}_{2}$ and moisture oxygen is also essential for the formation of corrosion products through reaction of free $\mathrm{Fe}^{2+}$ in anodic region with the hydroxyl ions (OH-) in cathodic region. Therefore oxygen permeability of cracked concrete will also be useful to control the corrosion of steel in concrete as dense uncracked concrete cover generally reduced the availability of oxygen on steel surface (Mohammed et al. 2003) and a slower cathodic reaction is expected for the regions with low oxygen availability. In a limited number of studies the oxygen permeability of cracked concrete and cementitious composites is evaluated. Mohammed et al. (2001a, b) studied the oxygen permeability of cracked concrete beams containing plain steel bar and deformed steel bar. Both beams were subjected to same load to create flexural cracks on the tension side of the beams. Results show higher oxygen permeability in the cracked beam reinforced with deformed bar than its counterpart plain bar reinforced cracked beam. Bigger width of cracks in the cracked beam reinforced with deformed bar than 


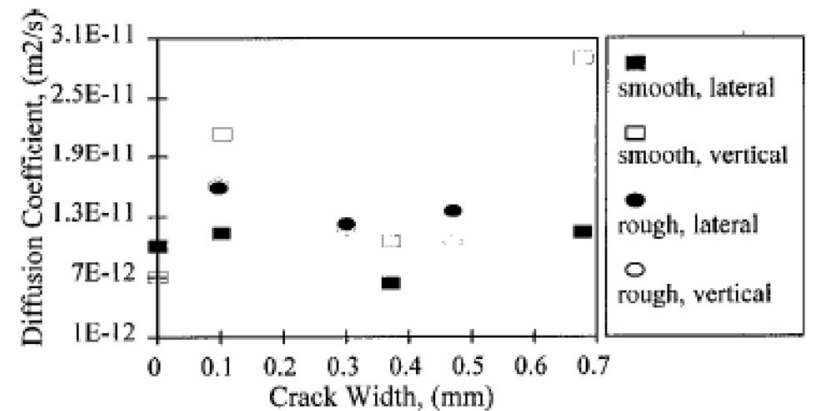

(a)

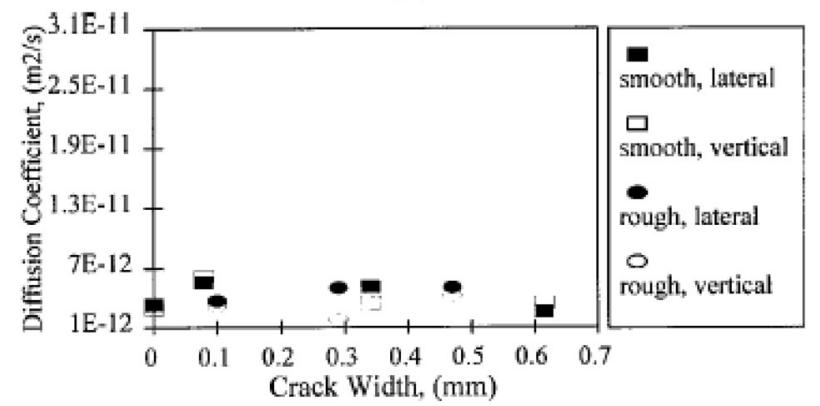

(b)

Fig. 13 Chloride diffusion coefficient of a cracked OPC concrete and b concrete containing $25 \%$ slag (Rodriguez and Hooton 2003).

those of plain bar RC beam is the reason for higher oxygen permeability observed in that study. The ribs in the deformed bar is the reason for bigger crack width in the former beam than the latter beam. In another study, Mohammed et al. (2002) reported significantly higher oxygen permeability of concrete made by higher $\mathrm{w} / \mathrm{c}$ ratio than the lower $\mathrm{w} / \mathrm{c}$ ratio for the same crack width of $0.3 \mathrm{~mm}$. Uncracked region showed significantly lower oxygen permeability than the cracked region irrespective of $\mathrm{w} / \mathrm{c}$.

\section{Effect of Healing of Cracks on Corrosion of Steel}

While concrete structures crack due to various reasons, some of the cracks also heal autogenously. Autogenous healing is the ability of concrete to heal its cracks itself. In the presence of moisture, free calcium hydroxide and calcium oxide in cement matrix reacts with $\mathrm{CO}_{2}$ in atmosphere and generates white colour calcium carbonate on the cracks faces and seals them either partially or fully. It has been observed in many studies that the smaller crack widths heal more easily than its wider counterparts in concrete and cementitious composites (Edvardsen 1999; Mohammed et al. 2003; Sahmaran and Yaman 2008; Nishiwaki et al. 2014). However, the healing of cracks either fully and partially significantly affect the penetration of chlorides and the corrosion of steel in concrete. Edvardsen (1999) found that the mean water flow rate of cracked concrete with $0.1 \mathrm{~mm}$ width decreased significantly than that of crack width of $0.3 \mathrm{~mm}$. The formation of calcium carbonate crystals on the crack face of $0.1 \mathrm{~mm}$ crack width is the reason for such low water flow rate this that study. Similar result is also reported

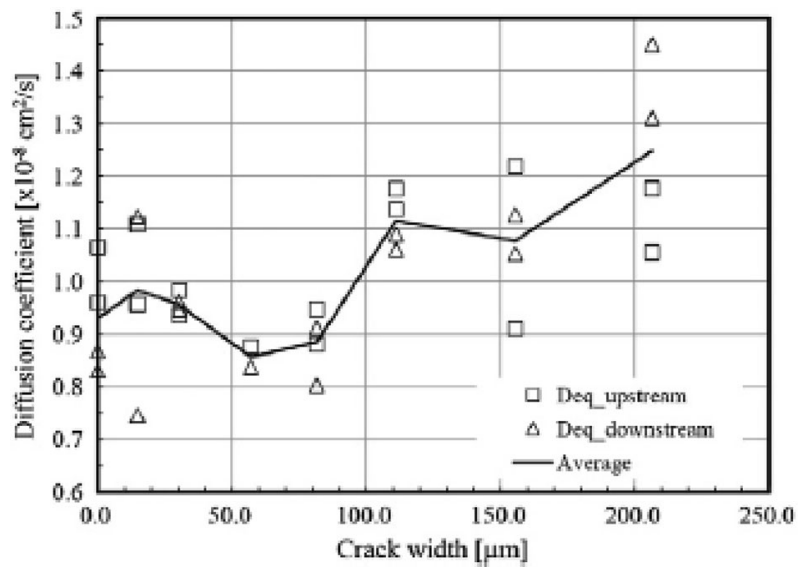

Fig. 14 Chloride diffusion coefficient of cracked concrete (Jang et al. 2011).

by Reinhardt and Jooss (2003) where cracked concrete having crack widths of $0.05,0.1$ and $0.15 \mathrm{~mm}$ reduced the water flow rate by 97,95 and $85 \%$, respectively after $300 \mathrm{~h}$ of flow test. The concrete in their study contained about $10 \%$ fly ash and $10 \%$ micro silica. According to them the significant reduction in water flow is due to self-healing of the cracks. Their research also shows that higher temperatures such as 50 and $80{ }^{\circ} \mathrm{C}$ favour the growth of self-healed products in the same crack width than at $20^{\circ} \mathrm{C}$, presumably due to the faster hydration reaction at higher temperature. Evidence of effect of self-healing of micro-cracks on the water permeability of fibre reinforced cementitious composites (FRCCs) is also observed in Nishiwaki et al. (2014)'s study where water permeability significantly reduced in cracked FRCC having crack widths below $0.2 \mathrm{~mm}$ due to the self-healing of those cracks. The only reported study where the corrosion current of steel was measured in selfhealed crack concrete containing fly ash and slag in a long term study of 15 years in marine environment (Mohammed et al. 2002). In that study three types of cements were used namely the OPC, slag cements of type A, B and C (SCA, SCB and SCC) and fly ash cement. Their results show that the small crack widths $(\sim 0.5 \mathrm{~mm})$ healed autogenously irrespective of type of binder in the concrete as evidenced by the measured low micro-cell current density shown in Fig. 15. Significantly lower current density were observed in above concretes containing smaller crack widths (e.g., below $0.3 \mathrm{~mm}$ crack width) (see the bottom graph in Fig. 15) than that of bigger crack widths as shown in top graph in Fig. 15. The formation of self-healed products on those smaller cracks is the cause for such low current density. Among various concretes having same crack width, the concretes containing fly ash and slag exhibited lower current density than that of control OPC concrete, even the concretes containing fly ash and slag having bigger crack widths (e.g., 0.2 and $0.3 \mathrm{~mm}$ ) exhibited lower current densities than OPC concrete with $0.1 \mathrm{~mm}$ crack width. The continued pozzolanic activity of fly ash and slag is responsible for the formation of more self-healed and hydration products on the crack surface which reduced the ingress of chloride ions and subsequent reduction of corrosion. 
OOPC DSCA $\triangle S C B \times S C C$ OFACB
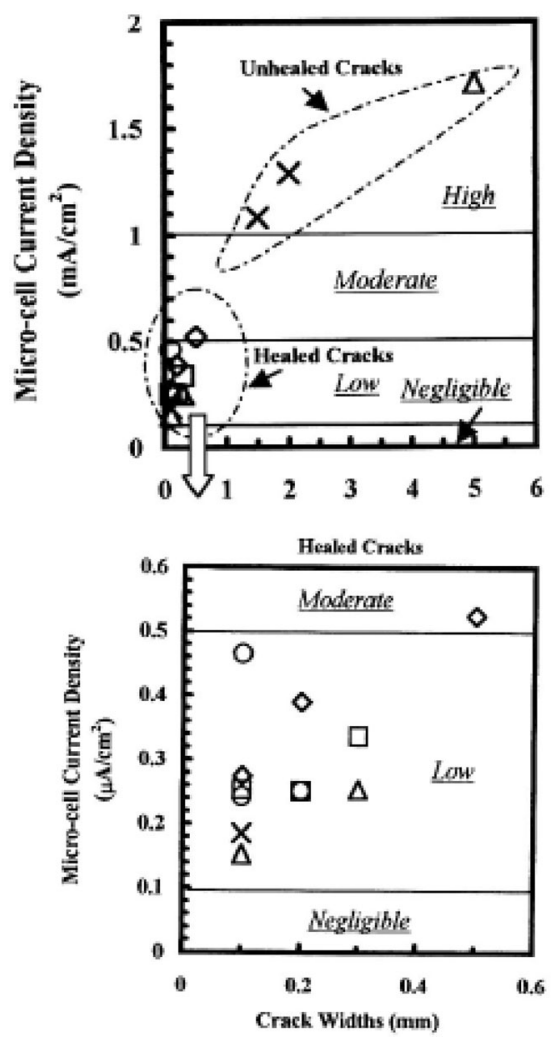

Fig. 15 Micro-cell current densities of unhealed cracks and healed cracks of various concretes after 15 years of marine exposure (Mohammed et al. 2002).

By comparing all reported results on the effect of crack widths on chloride ion or carbon-dioxide penetration and corrosion of steel in concrete no distinct trend can be established, except in few studies. If the effect of any particular crack width on chloride ion or carbon-dioxide penetration and corrosion of steel in concrete is considered, it can be seen that for the same crack width the penetration of chloride ions or carbon-dioxide and corrosion of steel is different for different $\mathrm{w} / \mathrm{c}$ ratios, SCMs types and their contents in the concretes of same concrete cover. It clearly shows that crack width is not the only factor accelerates the ingress of chloride ions or carbon-dioxide and corrosion of steel, quality of concrete also plays an important role. By lowering the w/c ratios and incorporating SCMs the concrete's porosity can be reduced and the ingress of chloride ions or carbon-dioxide, oxygen and moisture can be significantly reduced. Therefore, in addition to control the crack width the improvement of the quality of concrete is also important as slightly bigger crack widths of good quality concrete supposed to perform similar corrosion resistance to poor quality concrete with smaller crack widths. This is also valid for longitudinal cracks and for crack depth.

\section{Conclusions}

Corrosion of reinforcing steel in concrete is an important durability issue during service life of RC structures.
Cracking is also unavoidable in RC structures during its service life, which adversely affects its corrosion durability. While this is an important durability issue for $\mathrm{RC}$ not much research are reported in the literature especially in archival journals. Within available articles conflicting results on the effect of cracking on corrosion of steel in concrete are also reported. This paper reviewed the available results and the following can be summarised on the effects of cracking on corrosion of steel in cracked concrete:

(1) An increasing trend of corrosion of steel with widths of transverse cracks is observed up to crack width of $0.3 \mathrm{~mm}$. However, no such trend is observed beyond this crack width limit.

(2) The longitudinal cracks are found to be more severe in terms of corrosion of steel in concrete than transverse cracks of same width.

(3) Cracked SCM modified concretes exhibited superior corrosion resistance than cracked OPC concrete of same width of transverse as well as longitudinal crack.

(4) Among two reported studies on the effect of crack frequency (number of cracks in a certain length) on corrosion of steel in cracked concrete, no trend can be established. The theory proposed by Schiebl and Raupach (1997) seems more logical as it is evidenced in corrosion behaviour in multiple cracks of SHCCs.

(5) Corrosion of steel in cracked concrete supposed to increase with increase in crack depths as chloride penetration depth as well as chloride diffusion increase with increase in crack depths. The corrosion test result, however, shows an opposite trend presumably due to availability of less oxygen on the steel surface in cathodic region under thick concrete cover.

(6) Chloride ion penetration and diffusion is also influenced by the widths of transverse cracks, however, conflicting results are also reported in this case. Diffusion of carbon dioxide through cracks also increases with increase in crack widths and with increase in w/c ratios for a constant crack width.

(7) Self-healing of small crack widths reduced the water permeability and corrosion of steel in cracked concrete. The presence of cracks increase the oxygen permeability of in cracked concrete and it reduced with reduction of crack width and w/c ratio.

\section{Open Access}

This article is distributed under the terms of the Creative Commons Attribution 4.0 International License (http:// creativecommons.org/licenses/by/4.0/), which permits un restricted use, distribution, and reproduction in any medium, provided you give appropriate credit to the original author(s) and the source, provide a link to the Creative Commons license, and indicate if changes were made. 


\section{References}

Ahmed, S. F. U., \& Mihashi, H. (2010). Corrosion durability of strain hardening fiber reinforced cementitious composites. Australian Journal of Civil Engineering, 8(1), 27-39.

Al-Ahmad, S., Toumi, A., Verdier, J., \& Francois, R. (2009). Effect of crack opening on carbon dioxide penetration in cracked mortar samples. Materials and Structures, 42, 559-566.

Aldea, C. M., Shah, S. P., \& Kaee, A. (1999). Effect of cracking on water and chloride permeability of concrete. Journal of Materials in Civil Engineering, 11(3), 181-187.

Arya, C., \& Darko, F. K. O. (1996). Influence of crack frequency on reinforcement of corrosion in concrete. Cement and Concrete Research, 26(3), 345-353.

Audenaert, K., Marsavina, L., \& Schutter, G. D. (2009). Influence of cracks on the service life of concrete structures in a marine environment. Key Engineering Materials, 399, $153-160$.

Berke, N. S., Dallaire, M. P., Hicks, M. C., \& Hoopes, R. J. (1993). Corrosion of steel in cracked concrete. Corrosion, 49(11), 934-943.

Blagojevic, A., Fennis, S., \& Walraven, J. C. (2012). Impact of cracks on chloride induced corrosion and durability of reinforced concrete structures-A literature review. In International PhD student workshop on durability of reinforced concrete (pp. 80-91).

Dang, V. H., Francois, R., \& Hostis, V. L. (2013). Effects of precracks on both initiation and propagation of rebar corrosion in pure carbon dioxide. EPJ Web of Conferences, 56(06006), 1-11.

Darwin, D., Manning, D. G., \& Hognestad, E. (1985). Debate: Crack width, cover and corrosion. Concrete International, 7, 20-35.

Djerbi, A., Bonnet, S., Khelidji, A., \& Baroghel-bouny, V. (2008). Influence of traversing crack on chloride diffusion into concrete. Cement and Concrete Research, 38, 877-883.

Edvardsen, C. (1999). Water permeability and autogenous healing of cracks in concrete. ACI Materials Journal, 96(4), $448-454$.

Ismail, M., Toumi, A., Francois, R., \& Gagne, R. (2008). Effect of crack opening on the local diffusion of chloride in cracked mortar samples. Cement and Concrete Research, 38, 1106-1111.

Jang, S. Y., Kim, B. S., \& Oh, B. H. (2011). Effect of crack width on chloride diffusion coefficients of concrete by steady-state migration tests. Cement and Concrete Research, 41(1), 9-19.

Mehta, P. K., \& Gerwick, B. C. (1982). Cracking-corrosion interaction in concrete exposed to marine environment. Concrete International, 4, 45-51.

Miyazato, S., \& Otsuki, N. (2010). Steel corrosion induced by chloride or carbonation in mortar with bending cracks or joints. Journal of Advanced Concrete Technology, 8(2), 135-144.
Mohammed, T. U., Otsuki, N., \& Hamada, H. (2001a). Oxygen permeability in cracked concrete reinforced with plain and deformed bars. Journal of Cement and Concrete Research, 31(5), 829-834.

Mohammed, T. U., Otsuki, N., \& Hamada, H. (2003). Corrosion of steel bars in cracked concrete under marine environment. ASCE Journal of Materials in Civil Engineering, 15(5), 460-469.

Mohammed, T. U., Otsuki, N., Hisada, M., \& Shibata, T. (2001b). Effect of crack width and bar types on corrosion of steel in concrete. Journal of Materials in Civil Engineering, 13(3), 194-201.

Mohammed, T. U., Yamaji, T., Aoyama, T., \& Hamada, H. (2002). Marine durability of 15 year old uncracked and precracked concrete made with different cements. Journal of Materials, Concrete Structures and Pavements, JSCE, 54, 201-214.

Montes, P., Bremner, T. W., \& Lister, D. H. (2004). Influence of calcium nitrite inhibitor and crack width on corrosion of steel in high performance concrete subjected to a simulated marine environment. Cement and Concrete Composites, 26, 243-253.

Nishiwaki, T., Kwon, S., Homma, D., Yamade, M., \& Mihashi, H. (2014). Self-healing capability of fibre reinforced cementitious composites for recovery of watertightness and mechanical properties. Materials, 7, 2141-2154.

Otieno, M. B., Alexander, M. G., \& Beushausen, H. D. (2010). Corrosion in cracked and uncracked concrete-Influence of crack width, concrete quality and crack opening. Magazine of Concrete Research, 62(6), 393-404.

Otsuki, N., Miyazato, S., Doila, N. B., \& Suzuki, H. (2000). Influences of bending crack and water-cement ratio on chloride induced corrosion of main reinforcing bars and stirrups. ACI Materials Journal, 97(4), 454-464.

Poursaee, A., \& Hansson, C. M. (2008). The influence of longitudinal cracks on the corrosion protection afforded reinforcing steel in high performance concrete. Cement and Concrete Research, 38, 1098-1105.

Quero, V. J., Garcia, P. M., \& Bremner, T. W. (2010). Influence of concrete cracking on the corrosion of steel reinforcement. In P. Castro-Borges, et al. (Eds.) Concrete under severe conditions: Environment and loading (pp. 383-389). Boca Raton, FL: CRC Press.

Raupach, M. (1996). Corrosion of steel in the area of cracks in concrete laboratory test and calculation using transmission line method. In C. L. Page, et al. (Eds.) 4th International symposium on corrosion of reinforcement in concrete construction, July 1-4, 1996, UK.

Reinhardt, H. W., \& Jooss, M. (2003). Permeability and selfhealing of cracked concrete as function of temperature and crack width. Cement and Concrete Research, 33(7), 981-985.

Rodriguez, O. G., \& Hooton, R. D. (2003). Influence of cracks on chloride ingress into concrete. ACI Materials Journal, 100(2), 120-126.

Sahmaran, M., \& Yaman, I. O. (2008). Influence of transverse crack width on reinforcement corrosion initiation and 
propagation in mortar beams. Canadian Journal of Civil Engineering, 35, 236-245.

Schiebl, P., \& Raupach, M. (1997). Laboratory studies and calculations on the influence of crack width on chloride induced corrosion of steel in concrete. ACI Materials Journal, 94(1), 56-61.

Scott, A., \& Alexander, M. G. (2007). The influence of binder type, cracking and cover on corrosion rates of steel in chloride contaminated concrete. Magazine of Concrete Research, 59(7), 495-505.

Sistonen, E., Kari, O. P., Tukiainen, P., \& Huovinen, S. (2007). The influence of the crack width on the durability of different reinforcement bar materials. In F. Toutlemonde, et al. (Eds.) Concrete under severe conditions: Environment and loading-CONSEC07, Tours, France (pp. 419-428).

Stitmannaithum, B., Vu, H. Q., \& Tran, M. V. (2013). Chloride penetration into reinforced concrete structures. In Proceedings of 3rd international conference on sustainable construction materials and technologies, Kyoto, Japan.

Win, P. P., Watanabe, M., \& Machida, A. (2004). Penetration profile of chloride ion in cracked reinforced concrete. $\mathrm{Ce}$ ment and Concrete Research, 34, 1073-1079. 